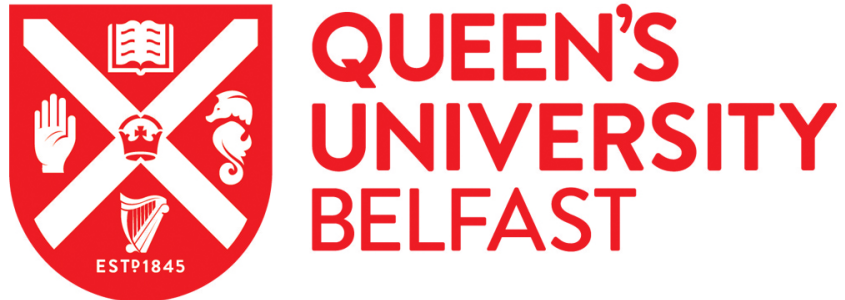

\section{Changes in soil solution heavy metal concentrations over time following EDTA addition to a Chinese paddy soil}

Wu, L. H., Luo, Y. M., Song, J., Christie, P., \& Wong, M. H. (2003). Changes in soil solution heavy metal concentrations over time following EDTA addition to a Chinese paddy soil. Bulletin of Environmental Contamination and Toxicology, 71(4), 706-713. https://doi.org/10.1007/s00128-003-0190-2

Published in:

Bulletin of Environmental Contamination and Toxicology

Queen's University Belfast - Research Portal:

Link to publication record in Queen's University Belfast Research Portal

\section{General rights}

Copyright for the publications made accessible via the Queen's University Belfast Research Portal is retained by the author(s) and / or other copyright owners and it is a condition of accessing these publications that users recognise and abide by the legal requirements associated with these rights.

Take down policy

The Research Portal is Queen's institutional repository that provides access to Queen's research output. Every effort has been made to ensure that content in the Research Portal does not infringe any person's rights, or applicable UK laws. If you discover content in the Research Portal that you believe breaches copyright or violates any law, please contact openaccess@qub.ac.uk. 
Bull. Environ. Contam. Toxicol. (2003) 71:706-713

C 2003 Springer-Verlag New York Inc.

DOI: $10.1007 / \mathrm{s} 00128-003-0190-2$

\section{Changes in Soil Solution Heavy Metal Concentrations over Time Following EDTA Addition to a Chinese Paddy Soil}

L. H. Wu, ${ }^{1,2}$ Y. M. Luo, ${ }^{1}$ J. Song, ${ }^{1}$ P. Christie, ${ }^{3}$ M. H. Wong ${ }^{4}$

${ }^{1}$ Institute of Soil Science, Chinese Academy of Sciences, Post Office Box 821 , Nanjing 210008, People's Republic of China

2 Laboratory of Terrestrial Ecological Processes, Institute of Applied Ecology, Chinese Academy of Sciences, Shenyang 110016, People's Republic of China

${ }^{3}$ Queen's University Belfast, Newforge Lane, Belfast BT9 5PX, United Kingdom

${ }^{4}$ Department of Biology, Hong Kong Baptist University, Hong Kong SAR, People's Republic of China

Received: 31 August 2002/Accepted: 16 June 2003

Phytoremediation is a developing technology that aims to extract or inactivate metals, metalloids and radionuclides in contaminated soils (McGrath et al., 2002). The plant availability and phytoextraction rate of some metals in soils are limited by their relatively low solubility and diffusion rate to the root surface. Chemical enhancements have been used to overcome this problem (Huang et al., 1997; Ebbs and Kochian, 1997), and the most promising application of this technology is for the remediation of lead contaminated soils using Indian mustard (Brassica juncea (L.) Czern.) in combination with EDTA (Blaylock, 2000). Despite the success of this technology, concerns have been expressed regarding the potential risk of leaching of EDTA to groundwater. EDTA can rapidly mobilize metals with a subsequent slow decrease in their concentrations, and high concentrations of heavy metals in the soil solution could pose an environmental risk in the form of ground water contamination (Cooper et al., 1999; Lombi et al., 2001). Some methods have been proposed to avoid this kind of environmental risk. Most studies have indicated that EDTA-metal chelates are resistant to microbial degradation (Tiedje, 1975; Means et al.; 1980; Hong et al., 1999). However, Belly et al. (1975) found good evidence for the microbial degradation of ${ }^{14} \mathrm{C}$-labeled EDTA within a few days of its addition to an aerated lagoon.

Little work has been done on the effects of EDTA on soil heavy metal concentrations over time following EDTA addition and the time limit of any such effects is still unknown. In this paper we describe a laboratory incubation experiment conducted to study the concentrations of four heavy metals and total organic carbon (TOC) in the soil solution of a Chinese paddy soil over time following application of two rates of EDTA. Soil collected from a field contaminated with $\mathrm{Cu}$ from wastewater was spiked with $\mathrm{Zn}, \mathrm{Pb}$ and $\mathrm{Cd}$ and equilibrated prior to the experiment. The results are discussed in relation to the potential efficiency of enhancement of heavy metal mobility by EDTA in phytoremediation procedures, and the risk of groundwater contamination.

\section{MATERIALS AND METHODS}

Soil (an Fe-accumulic Gleyi-Stagnic Antrosol) was taken from the plough layer $(0-10 \mathrm{~cm})$ of a paddy field in Jiangsu province, China, with a previous history of 
irrigation with $\mathrm{Cu}$-rich wastewater. The soil is a clay loam with a $\mathrm{pH}$ (in water) of 6.3 and had aqua regia-soluble concentrations of $\mathrm{Cu}, \mathrm{Zn}, \mathrm{Pb}$ and $\mathrm{Cd}$ of 158 , $42.7,6.55$ and $0.19 \mathrm{mg} \mathrm{kg}^{-1}$, respectively. The soil was air-dried and spiked with

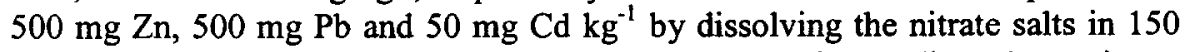
$\mathrm{mL}$ distilled water and mixing thoroughly into the soil to adjust the moisture content to about $40 \%$ of water holding capacity (WHC). The spiked soil was placed in a glasshouse for one month to allow it to equilibrate and to promote adsorption of the added metals. The soil was then air dried and sieved through a 2mm nylon mesh.

The laboratory incubation experiment comprised three treatments: (1) Control soil with no EDTA added (CK); (2) soil with EDTA added at the rate of $1 \mathrm{mmol} \mathrm{kg}$ (EDTA 1); and (3) soil with EDTA added at $3 \mathrm{mmol} \mathrm{kg}^{-1}$ (EDTA3). There were three replicates of each treatment in a fully randomized design. The EDTA treatments were set up using the following procedure. Air-dried metal-spiked $<2$ $\mathrm{mm}$ soil (2.7 kg, oven dry basis) was weighed into a large plastic container and the appropriate weight of EDTA Na salt dissolved in $600 \mathrm{~mL}$ distilled water was added. The soil was thoroughly mixed and divided into three $900-\mathrm{g}$ aliquots, each of which was transferred to a $1000-\mathrm{mL}$ plastic beaker. One soil moisture suction sampler (Rhizon SMS: Rhizosphere Research Products, Doderstraat 62, 6706JG Wageningen, The Netherlands) was installed in the centre of each pot to permit sampling of the soil solution. The soil moisture content of each beaker was adjusted to $80 \%$ WHC with distilled water. All beakers were covered with cling film to minimize water evaporation and placed in an incubator at a constant temperature of $25{ }^{\circ} \mathrm{C}$. The soil was adjusted regularly with distilled water by weight to maintain the moisture content at $80 \%$ WHC. Soil solution samples were collected from each beaker on eight occasions $(1,3,5,7,14,25,44$, and 91 days after EDTA application to the soil).

Each soil solution sample was separated into several portions for measurement of $\mathrm{pH}$ and determination of total organic carbon (TOC) and total $\mathrm{Cu}, \mathrm{Zn}, \mathrm{Pb}$ and $\mathrm{Cd}$ concentrations. The metals were determined using a Thermo Jarrell Ash inductively coupled plasma - atomic emission spectrophotometer (ICP-AES). TOC was determined using a Shimadzu 500A TOC Analyzer, and soil solution pH was measured using a $\mathrm{pH}$ meter. Data presented are means of three replicates together with standard errors of the means (SEM).

\section{RESULTS AND DISCUSSION}

Soil solution TOC in EDTA3 (the higher EDTA dosage studied) was much higher than that in EDTA1 (the lower EDTA dosage included) $(\mathrm{P}<0.01)$ which in turn was higher than the control shortly after EDTA addition (Figure 1a). TOC decreased with increasing incubation time in all treatments. From the first day after EDTA addition to the 14th day, the soil solution TOC was significantly different in EDTA1 and the control $(\mathrm{P}<0.05)$ but by the 25th day this difference had disappeared $(P>0.05)$. The soil solution TOC concentration in EDTA3 was significantly higher than EDTA1 and the control during the whole incubation 


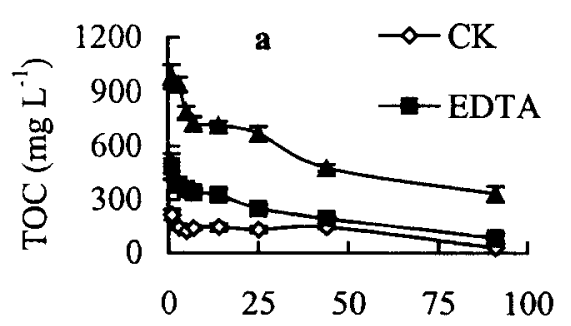

Time after EDTA addition (d)

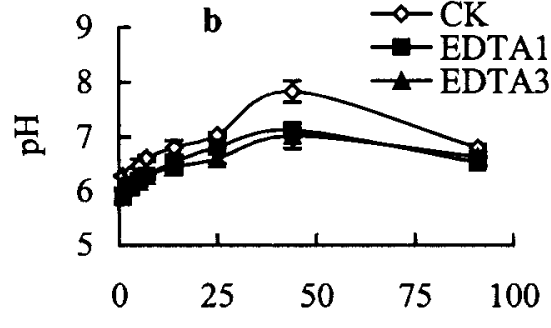

Time after EDTA addition (d)

Figure 1. (a) Soil solution TOC and (b) $\mathrm{pH}$ dynamics in the incubation experiment Bars: \pm standard error of the mean (SEM)

period $(\mathrm{P}<0.01)$.

Soil solution $\mathrm{pH}$ in the two EDTA treatments was slightly lower than in the control, possibly due to ion exchange between $\mathrm{Na}^{+}$and $\mathrm{H}^{+}$, but between the first and 25th days after EDTA addition there was no difference in soil solution $\mathrm{pH}$ among the three treatments (Figure $1 \mathrm{~b}$ ). Soil organic $\mathrm{C}$ degraded gradually with incubation time, and emission of $\mathrm{CO}_{2}$ may have resulted in the observed increase in solution pH. However, in the two EDTA treatments, EDTA may have degraded to low molecular weight acids and counteracted any $\mathrm{pH}$ increase, resulting in their lower soil solution $\mathrm{pH}$ values compared with the control. By the 44th day, soil solution $\mathrm{pH}$ reached its peak, and the control was higher than the EDTA treatments $(\mathrm{P}<0.05)$, but there was no difference between the two EDTA treatments. From the 44th day on, soil solution $\mathrm{pH}$ decreased and by the 91 st day there was no difference among the three treatments.

The concentrations of $\mathrm{Cu}, \mathrm{Zn}, \mathrm{Pb}$ and $\mathrm{Cd}$ in the soil solution followed the sequence EDTA3 $>>$ EDTA $1 \gg>$ Control, and this trend remained unchanged throughout the incubation period (Figure 2). One day after EDTA addition the $\mathrm{Cu}$ concentration in the soil solution was $0.22 \mathrm{mg} \mathrm{L}^{-1}$ in the control, $14.5 \mathrm{mg} \mathrm{L}^{-1}$ in the EDTA1 treatment and $44.2 \mathrm{mg} \mathrm{L}^{-1}$ in EDTA3, and thereafter declined slowly. Zinc, $\mathrm{Pb}$ and $\mathrm{Cd}$ showed similar trends, but the rates of decrease with time were higher for $\mathrm{Zn}$ and $\mathrm{Pb}$ than for $\mathrm{Cu}$ and $\mathrm{Cd}$. On the first day after EDTA addition there was a $\mathrm{Zn}$ concentration of $295 \mathrm{mg} \mathrm{L}^{-1}$ in EDTA3 and this represented $54.4 \%$ of the soil total $\mathrm{Zn}$ concentration. This relatively high concentration and high availability of $\mathrm{Zn}$ in the soil solution immediately after EDTA addition may have been the main reason why $\mathrm{Zn}$ mobility decreased quickly. Lead was easily precipitated by other ions in the soil, and its activity also declined much more quickly than that of $\mathrm{Cu}$ or $\mathrm{Cd}$.

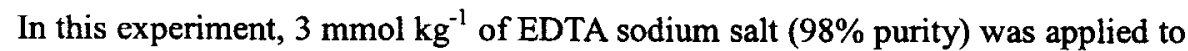
the EDTA3 treatment. The soil water content in each pot was adjusted to $44.6 \%$ (equivalent to $80 \%$ of WHC) when the soil solution samples were collected. If 

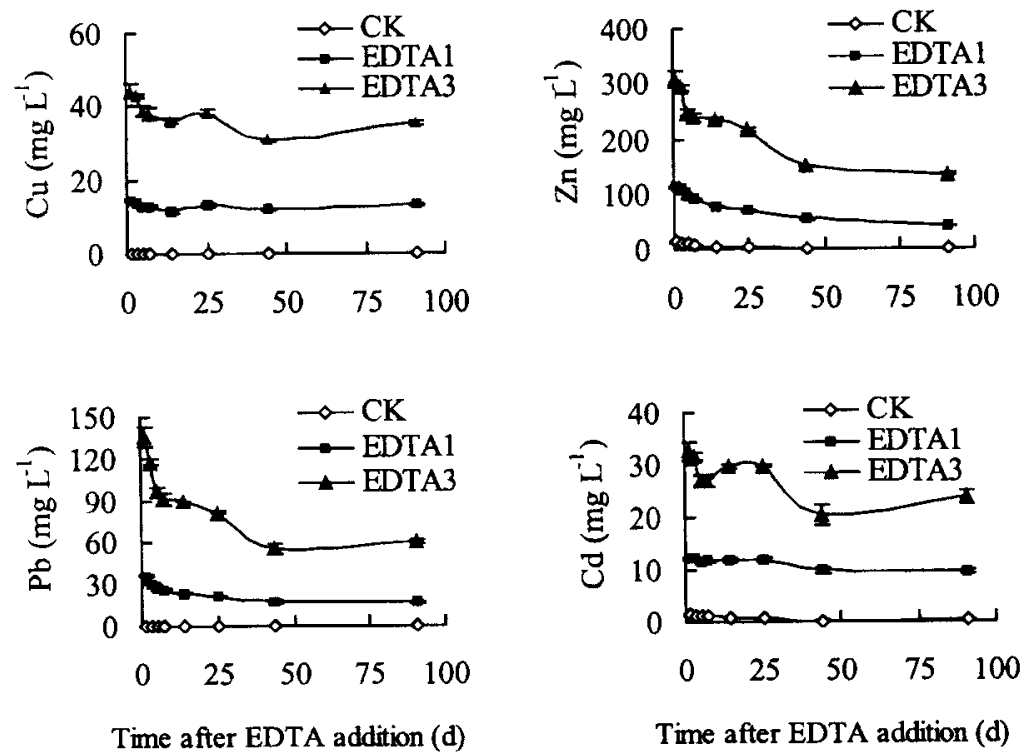

Figure 2. Soil solution $\mathrm{Cu}, \mathrm{Zn}, \mathrm{Pb}$ and $\mathrm{Cd}$ concentrations during incubation

EDTA was distributed uniformly in the soil solution and no EDTA was adsorbed by soil colloids and plant roots, then the initial organic EDTA carbon in the soil solution would have been $264 \mathrm{mg} \mathrm{L}^{-1}$ for EDTA1 and $792 \mathrm{mg} \mathrm{L}^{-1}$ for EDTA3. If we disregard the effects of plant root exudates on EDTA degradation, then we can estimate the EDTA degradation rate. One week later (on the 7th day of incubation), soil solution TOC concentrations were 69.4 and $72.0 \%$ of the added amount in EDTA1 and EDTA3. Fourteen days after EDTA addition, soil solution TOC decreased to $46.3 \%$ in EDTA1 and $67.9 \%$ in EDTA3. By the 44th day, the values were $19.8 \%$ for EDTA1, and $42.2 \%$ TOC for EDTA3 and most of the EDTA was degraded. However, between days 44 and 91 soil solution TOC remained nearly constant, indicating that EDTA was stable and resistant to degradation. The EDTA degradation dynamics can be simulated using equations (Figure 3). In this graph we have plotted net TOC, that is soil solution TOC in EDTA-amended soil minus soil solution TOC in the unamended control. The equations derived were: Net TOC $\left(\mathrm{mg} \mathrm{L}^{-1}\right)=278 \mathrm{e}^{-0.0364 t}(\mathrm{t}=0-44$ days $)$ for EDTA1 and Net TOC $\left(\mathrm{mg} \mathrm{L}^{-1}\right)=767 \mathrm{e}^{-0.0183 t}(\mathrm{t}=0-44$ days) for EDTA3 (Figure $3)$. These results indicate that the EDTA degradation rate in the soil was more rapid than reported in studies by Hong et al. (1999), Bolton et al. (1993), Madsen and Alexander (1985), and Tiedje (1975), who all found that EDTA was quite resistant to biodegradation. However, our data (which indicate that EDTA can be biodegraded within a short time) agree with other studies (Nortemann, 1992; Belly et al., 1975). In the experiment of Hong et al. (1999) only under the most favorable conditions with acclimated cultures was some EDTA biodegradation (3$50 \%$ ) observed. Madsen and Alexander (1985) also found that wastewater microorganisms could not degrade EDTA at low concentrations $\left(<1 \mathrm{mg} \mathrm{L}^{-1}\right)$ in 72 


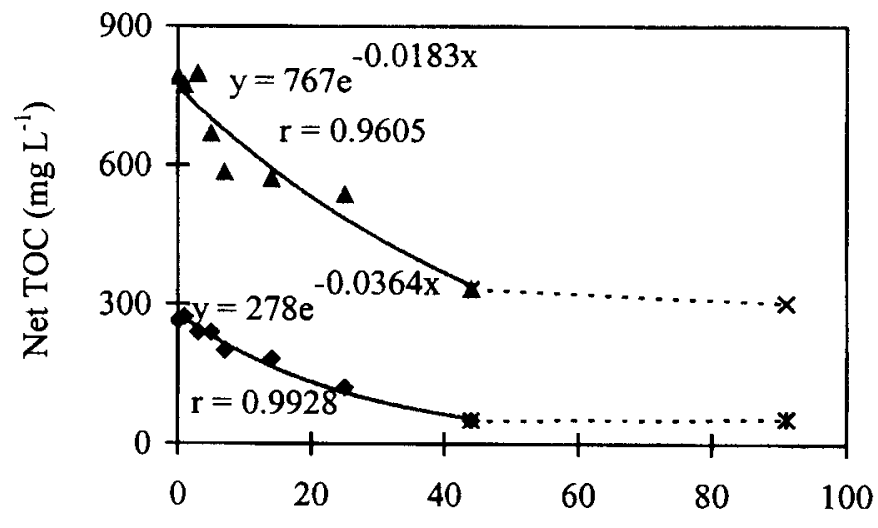

Time after EDTA addition (d)

Figure 3. EDTA degradation during the time course of the incubation experiment

days even with supplementary sodium acetate as a carbon source. Kari and Giger (1996) also found very little EDTA removal by biological or chemical means in wastewater plants. Their results were obtained under hydroponics culture conditions or low EDTA dosage. Some other papers reported EDTA could also be quickly degraded. When $0.1 \% \mathrm{w} / \mathrm{v} \mathrm{NaFe}$-EDTA was used as the sole carbon source in an aerated lagoon, biodegradation was as high as $89 \%$ after 5 days (Belly et al., 1975).

Nortemann (1992) found that certain mixed cultures isolated from sewage were capable of utilizing EDTA as a sole carbon and nitrogen source, and under certain conditions there were species that could biodegrade EDTA completely and very quickly. Our results show that, at the early stages of incubation, when the EDTA concentration was highest, its degradation rate was also high, and this agrees with Belly et al. (1975). However, when most of the EDTA was degraded, soil microorganisms may have used carbon sources other than EDTA, so that the EDTA degradation rate decreased, and soil solution TOC remained stable at a low level (Figures 1a and 3). This may explain why EDTA was resistant to biodegradation at low concentrations. EDTA disappearance may occur in five ways, namely biodegradation, phytodegradation, chemical degradation, soil sorption, and evaporation (Means, 1980). It was clear that the degradation of EDTA in dark incubation experiments was biological (Belly et al., 1975). However, in sterile solution, the EDTA loss in dark conditions was mainly through chemical degradation and soil adsorption, and was $28-52 \%$ within 173 days of incubation, and EDTA loss by evaporation was minor (Means et al., 1980). According to Means et al. (1980), the difference between dark and light conditions was about $6-11 \%$. We conducted our incubation experiment in a growth chamber without light and this may have resulted in lower EDTA degradation rates. 

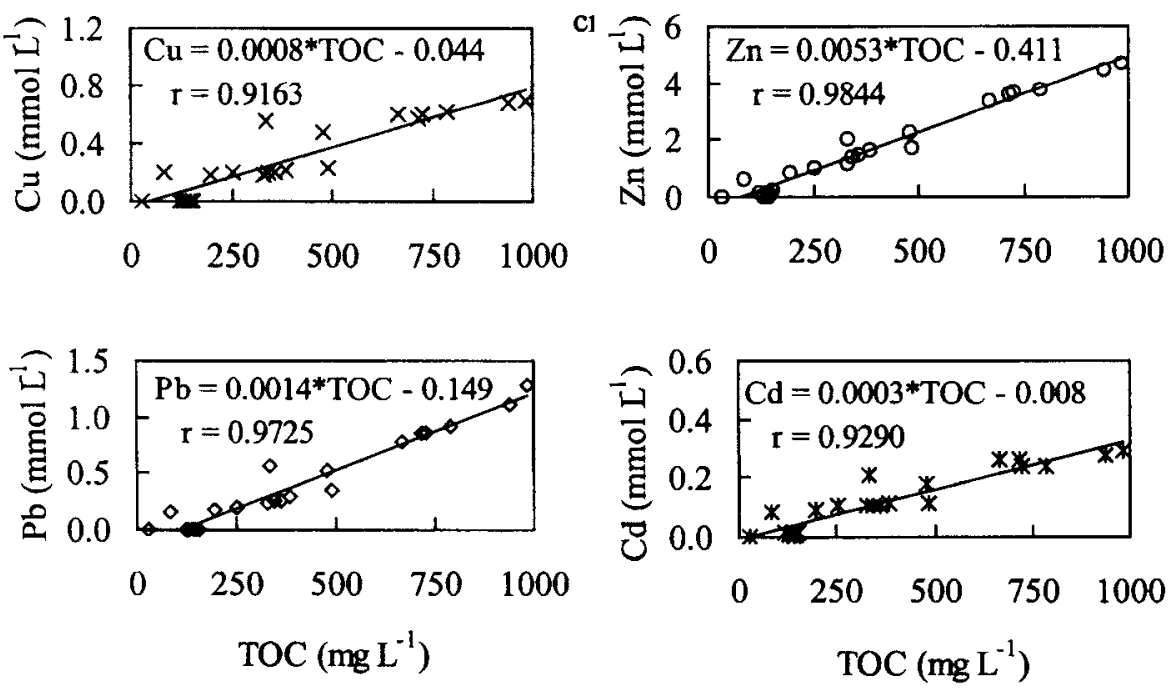

Figure 4. Relationships between the metals and TOC in the soil solution

The purpose of EDTA application is to promote heavy metal mobility and thereby increase plant heavy metal uptake and so enhance phytoremediation efficiency (Huang et al., 1997; Ebbs and Kochian, 1997). The EDTA mobilized metals rapidly and then their concentrations decreased slowly over a long time period. This may assist plant metal uptake. However, when plants are harvested and phytoremediation ends, high concentrations of heavy metals chelated by EDTA can remain in the soil. We found good agreement between the soil solution TOC concentrations and total molar concentrations of $\mathrm{Cu}, \mathrm{Zn}, \mathrm{Pb}, \mathrm{Cd}$ in the soil solution (Figure 4). This indicates that most of the heavy metals were complexed by EDTA. Similar observations were made by Lombi et al. (2001). Thus, possible side effects of EDTA application should be considered. At the end of the experiment, soil solution TOC concentrations and $\mathrm{Cu}, \mathrm{Zn}, \mathrm{Pb}$, and $\mathrm{Cd}$ concentrations were all very low, but they would still be high enough to result in heavy metal leaching to ground water in the field. If low concentrations of EDTA are resistant to degradation, the chelate may persist and affect heavy metal behavior in the soil over long time periods. In addition to the ground water contamination risk, some other possible effects of EDTA have also been noted. For example, Grcman et al. (2001) reported that EDTA is toxic to soil fungi and increases environmental stress of the soil microfauna. High concentrations of heavy metals in soil also affect plant growth of successive crops especially at the early stages, and decrease maize crop yield significantly (Lombi et al., 2001). Thus, despite the success of chelate enhancement of heavy metal mobility, the potentially serious consequential effects should always be taken into account in phytoremediation schemes. 
Acknowledgments. We thank the National Natural Science Foundation of China (Projects 40001013 and 40125005), the National Key Basic Research and Development Program (Project 2002CB410809) and the Research Foundation of the Key Laboratory of Terrestrial Ecological Processes, Chinese Academy of Sciences, for generous financial support. Presented at the First International Conference on Pollution Eco-Chemistry and Ecological Processes, Shenyang, China, August 27-31, 2002.

\section{REFERENCES}

Belly RT, Lauff JJ, Goodhue CT (1975) Degradation of ethylenediaminetetraacetic acid by microbial populations from an aerated lagoon. Appl Microbiol 29:787-794

Blaylock MJ (2000) Field demonstration of phytoremediation of lead contaminated soils. In: Terry N, Banuelos GS (ed) Phytoremediation of contaminated soil and water. Lewis Publishers, Boca Raton, FL, p 1

Bolton H, Li SW, Workman DJ, Girvin DC (1993) Biodegradation of synthetic chelates in subsurface sediments from the southeast coastal plain. J Environ Qual 22:125-132

Cooper EM, Sims JT, Cunningham SD, Huang JW, Berti WR (1999) Chelateassisted phytoextraction of lead from contaminated soils. J Environ Qual 28:1709-1719

Ebbs SD, Kochian LV (1997) Toxicity of zinc and copper to Brassica species: Implication for phytoremediation. J Environ Qual 26:776-781

Grcman H, Velikonja-Bolta S, Vodnik D, Kos B, Lestan D (2001) EDTA enhanced heavy metal phytoextraction: Metal accumulation, leaching and toxicity. Plant Soil 235:105-114

Hong PKA, Li C, Banerji SK, Regmi T (1999) Extraction, recovery, and biostability of EDTA for remediation of heavy metal-contaminated soil. J Soil Contam 8:81-103

Huang JW, Chen JJ, Berti WR, Cunningham SD (1997) Phytoremediation of leadcontaminated soils: Role of synthetic chelates in lead phytoextraction. Environ Sci Technol 31:800-805

Kari FG Giger W (1996) Speciation and fate of ethylenediaminetetraacetate (EDTA) in municipal waste water treatment. Water Res 30:122-134

Lombi E, Zhao FJ, Dunham SJ, McGrath SP (2001) Phytoremediation of heavy metal-contaminated soils: natural hyperaccumulation versus chemically enhanced phytoextraction. J Environ Qual 30:1919-1926

Madsen EL, Alexander M (1985) Effects of chemical speciation on the mineralization of organic compounds by microorganisms. Appl Environ Microbiol 50:342-349

McGrath SP, Zhao FJ, Lombi E (2002) Phytoremediation of metals, metalloids, and radionuclides. Adv Agron 75:1-56

Means JL, Kucak T, Crerar DA (1980) Relative degradation rates of NTA, EDTA and DTPA and environmental applications. Environ Pollut (Ser B) 1:45-60

Nortemann B (1992) Total degradation of EDTA by mixed cultures and a bacterial isolate. Appl Environ Microbiol 58:671-676 
Tiedje JM (1975) Microbial degradation of ethylenediaminetetraacetate in soils and sediments. Appl Microbiol 30:327-329 